\title{
THE LIBRARIAN AS SOCIAL ARCHITECT: \\ Creating a Community for Learning and Research at the Dana Library at Rutgers-Newark
}

\author{
BYLYNN S. MULLINS
}

Ms. Mullins is Director of the John Cotton Dana Library

Academic library facilities planning in the current climate of rapid technological change and severe economic constraint is a difficult process that generally begins with and builds on a needs assessment and prioritization of concerns. The process requires spatial thinking about adjacencies and proximities and administrative and functional efficiencies, and is based on a series of projections and estimations of growth and change in resources and information services. The difficulty of these considerations notwithstanding, the most critical aspect of the planning challenge is, however, an underlying conceptual one-the understanding and anticipation of the programmatic and related user needs of the campus and the broader community and the way that the library is able to respond to these needs and shape its programs accordingly. In effect, the library uses the medium of architecture to express the nature of its relationships with its constituencies. When viewed from this perspective, the challenge presents the opportunity to create an environment for learning and research that reflects the library's values and beliefs and that gives a clearer focus to its educational role. The challenge is energizing and enabling, and librarians who are engaged in the process have the opportunity to become, in a sense, social architects who can translate their vision of what they believe the library is or can be into a new social reality.

The John Cotton Dana Library of the Rutgers University Libraries, in Newark, has had the opportunity to create the kind of library environment that it sought for its campus and community (within, of course, the restrictions of an extremely tight construction budget) in the planning for a two-story addition to and renovation of its facility during the past few years. (It has been at its present site since 1967 with a new wing added in 1977.) The Dana Library is an integral part of the 
eighteen-library Rutgers University Libraries system, sharing in the development and management of all of the Libraries' collections, the development and accessing of a unified database of their holdings, the borrowing and lending of resources throughout the three campuses, and the development and monitoring of administrative and service policies, programs, and structures. As a regional campus library, the Dana Library supports the programs on the Newark Campus and has strong linkages with its neighboring educational and cultural institutions in Newark and is an active participant in resource-sharing arrangements in the city, the region, the state, and the broader scholarly community.

The Dana Library considers itself to be an "involving" library in the sense that Kuh, Schuh, and Whitt (1991) used the concept of an "involving college": one that fosters student learning and development through effective out-of-classroom experiences. ${ }^{1}$ Building on this concept, an "involving library" can be said to value learning and is itself involved in the process. It is a library that is organizationally involved with the campus so that it can, many times in partnership with other units, actively participate in the teaching and learning processes. The design of the new space at Dana was a way of planning further for this kind of involvement, collaboration, and interaction, extending the concept beyond its initial focus on undergraduates to also include graduate students, faculty, scholars and students from other institutions, and members of the community.

The perspective brought to the planning was, essentially, ecological in nature, with considerable attention directed at the needs of the Rutgers-Newark Campus within the context of the global information environment. This approach provided the framework within which the Library could think about its role in the support and encouragement of learning and research, allowing it to consider the way that new space and spatial arrangements could lead to a greater effectiveness and efficiency. To gain an understanding of the campus as the background for the planning, it is helpful to review some of the changes that the Newark Campus had experienced and the new directions for future growth that were emerging.

\section{The Rutgers-Newark Campus and Community}

The Rutgers-Newark Campus had grown dramatically over the past twenty-five years, evolving from a predominantly undergraduate, urban commuter campus to one that was rapidly becoming a university center of distinction in northern New Jersey, with strong graduate programs 
and professional schools and two on-campus residences that reflected the city's economic and social vitality. The Campus had been building on its long-term strengths in the biosciences, chemistry, management, criminal justice, nursing, and law to the point where there were eight doctoral and thirteen masters' programs offered in Newark that complemented the programs in its two undergraduate colleges. The recent opening of the new Center for Molecular and Behavioral Neuroscience, with its planned collaborative research programs in psychobiology and biomedicine, and the restructuring of the curriculum of the graduate business programs were further examples of this new phase of development. The undergraduate programs experienced a similar strengthening, with, for example, the development of a new general education program, the integration of the visual and performing arts programs into a single arts major, and the receipt of a major grant to encourage students to study and do work in the biological sciences.

The Newark Campus had a long history of participating in collaborative programs with the other major educational and cultural institutions in Newark. Of special note were the cooperative efforts between the four public institutions of higher education in Newark-the New Jersey Institute of Technology, the University of Medicine and Dentistry of New Jersey, Essex County College, and Rutgers-Newark-structured through the Council for Higher Education in Newark (CHEN) consortium. Most recently, Rutgers-Newark and the New Jersey Institute of Technology announced the initiation of a new consortial relationship between the two neighboring institutions that would further strengthen the academic resource base in Newark and, at the same time, effect desired economies.

\section{The Dana Library and the Newark Campus}

The Dana Library's resources and services had been developing in concert with the evolution of the programs of the Campus. Recent years had seen the strengthening of the business and management, the bioscience, chemistry, neuroscience, and nursing collections, and the acquisition of two new important branch collections, including the internationally renowned Institute of Jazz Studies. Though clearly not as strong as necessary, the collections had gained in quantity and quality to the point where four subject areas-business, nursing, criminal justice, and jazz-were designated the research collections for the University. The Libraries' long-range plan, ${ }^{2}$ recognizing the need for major collection development in the various Rutgers libraries, set a 
target for a minimal research collection size of 750,000 volumes in Newark, to be reached over a ten-year period. This target figure, combined with the delineation of the space needs of the existing collections, served as the frame for the planning for appropriate space for the collections. All of the Dana collections were growing, and large numbers of stack sections, particularly in the reference, periodical, and document areas, were approaching eighty-percent capacity, with recent years seeing extensive shifting of materials and the loss of seating to accommodate additional shelving.

Considerable advances had been made in the incorporation of the new technologies into the Library's service programs. A Computers in Curricula grant awarded in 1988 by the New Jersey Department of Higher Education permitted the Library to acquire and network CDROMs as a way of anticipating and responding to the new interest in database searching by undergraduates that would, in all likelihood, be engendered by the new general education program just put in place by the Faculty of Arts and Sciences. The implementation of this project at a time when CD-ROM networking was still in its infancy generated a great deal of attention in the Campus and the library system and in the broader library and vendor communities. At the same time, the Library served as a test site for the development of search software by one of the major vendors in the field, developed relationships with other vendors and systems designers, and put together several networking configurations and workstation clusters.

Grouped largely by subject, the workstations were distributed throughout the reference room in close proximity to the printed indexes and other materials on the same subject, with (hand crafted) colored banners indicating their location. This placement reflected the Library's commitment to the integration of all information formats into the library research process. In a brief time period, the new research tools became a central component of the public services program, with the librarians devoting a great deal of time to helping students and others learn how to use them. The new tools were incorporated into the Library's bibliographic instruction program, and a special effort was made to reach out to the faculty on the Campus, in concert with the FAS-N Library Committee (the "Faculty Outreach Program"), to ensure that the faculty were cognizant of the way that libraries, and the Dana Library in particular, were changing. This led to the development of joint grantwriting and administration projects with the faculty and others on the campus in the areas of information literacy, information management, 
and mentoring for curriculum development, and on the development of a partnership program with a local high school to foster knowledge of the new "electronic library."

The Library's projects were considered to be successful, with the Campus' undergraduates, graduates, and faculty, as well as students from other schools and colleges in the region (including many of the students at the neighboring NJIT), and the general public making extensive usage of the Library's databases and other services. The first partial year of operation (1989/90), for example, saw an estimated 30,000 usages of selected CD-ROM databases. There were significant increases in usage in almost every public service area-reference queries handled, circulation, reserve, intralibrary loan, bibliographic instruction, media usage, and serials usage.

The Library continued its leadership in information management and retrieval, working in concert with the Campus' Computing Services department on the development of wide-area access to the CD-ROMs via the campus network and on the joint design of teaching programs that fostered, among other services, the use of the information resources made available through the electronic Internet. It acquired additional electronic resources, all the while focusing attention on their access and usage and relationship to student projects and faculty research interests. The introduction by the Libraries of its new online public access catalog during this period served to draw further attention to the availability of materials in the different Rutgers libraries. It put even more demands on the intralibrary loan operation, which, in order to cope, had to be moved to larger quarters on another floor.

The Dana Library had long had a reputation for the helpfulness of the librarians and staff, who devoted a great deal of time and energy to assisting students with their research projects. The reference deskone of the largest in any library-symbolized the primacy of the reference function. It was more than a desk in the reference room: it was a center where active learning took place on a daily basis, with students and librarians interactionally engaged in the process. With the advent of the new electronic sources, the librarians' technological expertise assumed a new prominence on the Campus, and the combination of the strong service ethic with the new technical proficiencies served to delineate the Library's role in a new way.

The Campus was changing and the Library was changing along with it. New linkages had been made to ensure attunement to needs, and responses made through the changing dimensions of the service pro- 
grams. The physical setting of the public services area, particularly the reference room, however, was posing a problem, since there was limited space available for the accommodation of the new CD-ROMs and other workstations and terminals. The expansion of the reference collections, the proliferation of the machines, and the large numbers of patrons led to a crowdedness that required immediate alleviation. This was, clearly, a priority for the new addition.

One collaborative program that also required new space was the exhibits program, an outreach program that, with faculty and student groups, including the College Honors Program, planned exhibits to celebrate a person or event or campus activity. Community organizations, ranging from the Newark Public Library to the Museo del Barrio to the Portuguese Continental Union, began to join the Library as partners in the sponsorship and preparation of exhibits, enriching the program further with the uniqueness of their resources and the energy of their involvement. The program gave a visual highlight to some of the Library's activities, serving as an educational outreach program that fostered learning in an alternative way. The program also had another benefit: it served to concretize and strengthen further the ties between the campus, the community, and the Library. Additional space in the new facility could enhance the program's objectives.

\section{The Institute of Jaz: Studies}

The Institute of Jazz Studies, a unique research facility and archival collection that had come to the Newark Campus in 1966, had recently been made a branch of the Library. During its years at Rutgers, the collections had quadrupled in size. There were now more than 100,000 sound recordings in all formats, from phonograph cylinders and piano rolls to videocassettes and laser discs; more than 5,000 books on jazz and related subjects, including discographies, bibliographies, and dissertations; comprehensive holdings in jazz periodicals from throughout the world; in-depth interviews with notable jazz musicians; and extensive vertical files on individuals and topical areas, a large collection of photographs, sheet music, big band arrangements, musical instruments and other realia and memorabilia. A concerted attempt had been made to increase the accessibility of the collections through the development of a new automated shelflist of the audio recordings as a way of supplementing the ongoing cataloging projects. Preservation was always a major concern, and considerable work had been done to microfilm and bind the rare periodicals. 
The Institute's constituency was a broad one, ranging from students to scholars, and including teachers, authors, collectors, musicians, the members of the media, record companies and producers, other libraries and archives, and arts agencies and jazz organizations. The Institute was the publisher of a scholarly journal, a monograph series, and a cataloging index. In concert with the campus, it was committed to the development of outreach programs that brought its resources to a wider public that included the organization of seminars, conferences, concerts, and exhibits, and the hosting of a weekly radio program, "Jazz from the Archives," heard on WBGO-FM, Newark's National Public Radio affiliate and the metropolitan area's only full-time jazz station. It was an invaluable resource for the city, and it was envisioned that the planned development of the New Jersey Performing Arts Center, to be located not far from the campus, would direct new attention at its resources and service programs. Moreover, it was also expected that the new integrated undergraduate arts program on the campus would further generate an interest in jazz, as would the developing plans for an expanded American Studies program.

There were, however, serious environmental problems that the Institute was facing that were affecting its ability to carry out its activities. Located in Bradley Hall, there was literally no room for any expansion at a time when the Institute's growing reputation was attracting a record number of donations. Some short-term measures had been taken to alleviate the severity of the storage problem, such as the annexation of a hallway outside of the Institute and the use of some space at Dana, but the space needs were acute. The Bradley Hall facility also presented environmental problems that, though somewhat ameliorated by the recent replacement of a major air conditioning unit in the record storage area, still subjected the collections to the possibilities of floods. The temperature controls were inappropriate for the collections and there were limitations in the lighting. Moreover, the space issue had affected the users, particularly the visiting scholars, with minimal space available for their research. Space was also needed for the preparation and display of exhibits, for the holding of seminars, and for the planning of performances. There was, clearly, a critical need to preserve and enhance this most distinguished collection and to give it a new visibility.

\section{The Planning Process for the New Facility}

The planning process began formally in 1988 with the initiation of a needs assessment that made a number of assumptions. These assump- 
tions were that the plans for the new Library facility would allow for a ten-year period of major collection development; that this development would be guided by the Libraries' new long-range plan and the conceptualization of the regional campus library and its role within the University Libraries system that was detailed in The Rutgers University Libraries: A Unified System (1988); that the new facility would be planned to accommodate the appropriate balance of print and non-print materials insofar as it could be reasonably predicted; that a campus-based local area network would be in place to facilitate access to the Libraries' online catalog and other information sources; that workstations that could accommodate the new research methodologies would be a critical component of the facility and that provision would be made to bring appropriate cabling to a wide variety of locations throughout the building; that the academic and research programs on the Newark Campus would continue to evolve in accordance with the Campus mission and goals; and that the linkages to the institutions of higher education and cultural concern within the Newark community would continue to be significant, as would the linkages to the public and private sectors of the state. $^{3}$

The Dana librarians and staff members were assigned areas of responsibility (users, collections, reference, the Institute of Jazz Studies, media, seating, special rooms, the circulation and lobby areas, Technical Services, administrative offices, local area networks and telecommunications, and aesthetic considerations) and data were gathered and analyzed. There was extensive consultation with Campus and Libraries personnel, attendance at seminars, and visits to other libraries, and a document was put together that detailed the Library's overall needs. ${ }^{4}$ The actual space available for the new addition was smaller than what was needed-there would be 39,434 net assignable square feet added to the existing 88,600 square foot facility-so the task turned to the prioritization of needs and to the development of a more limited concept document. Moreover, budgetary constraints meant that one of the two floors had to be a shell, to be finished at a later date.

The process was collaborative, with a new campus-wide committee formed to assist the Library faculty and staff with the decision-making and concept development. The concept focused on the relocation of the Institute of Jazz Studies to the new fourth floor, which would have the appropriate environmental controls, the linking of the Institute with Dana's Media Services department, and the development of new spaces on that floor for shared listening and viewing facilities and for media- 
equipped group study rooms. There would be a multipurpose room for film and video showings, for performances, and for seminars, and a gallery for general library and jazz exhibits. The third floor, when completed, would house the growing collections, individual and group study rooms, and additional carrels, tables, and lounge seating. The renovation on the main floor would address the public services needs through the expansion of the reference area into the lobby and out onto the plaza and the upgrading of the lobby area.

A library planning consultant was hired to assist with the detail planning, the architectural firm of Faridy Thorne Fraytak, P.C. Architects was retained, and the formal development of the building program was undertaken. The architect was unusually sensitive to the needs of the Library, accompanying the librarians on visits to other libraries and media facilities and devoting much time to the consideration of the pressing functional issues. The Library was also fortunate to work with a University architect who coordinated the process, who had a similar attunement to and concern about the needs. A second consultant knowledgeable about the preservation and storage of audio collections was also made available by the architect. As part of the process, the Library also developed plans for the renovation of the periodicals and microforms area on the lower level, for the Technical Services area, and for the administrative offices, which would be undertaken if funding permitted. The planning process, because of its collaborative nature, was a satisfying one for the librarians (even when budgetary concerns made project scope reductions necessary).

\section{The Jass/Media Complex}

The proposed juxtaposition of the Institute with Dana's Media Services department would create a new jazz/media/gallery/special collections complex that could strengthen the respective units by bringing them together in an environmentally sound and functionally efficient facility. It offered the potential for the sharing of audiovisual facilities and staff and for the coordination of overlapping services, including the transfer of records and tapes from the Institute to Media Services for more casual listening, Moreover, it would also be advantageous for the Institute's users to be able to have easy access to Dana's extensive reference collections. There would also be advantages in the sharing of a Special Collections room in terms of the required environmental controls and security. The exhibition area would not only provide for the permanent and topical display of the Institute's collections, including its musical 
instruments, photographs, and art work, but would also make available a space for many of Dana's exhibits and opening receptions. There would be specially designed kiosks that, if funding permitted, could be used to house interactive displays of interest to the campus and the community. The new focus on media and multimedia would highlight an educational resource that was undergoing extensive technological change and that would introduce new alternative strategies for learning. The media-equipped group study rooms, to be used by all students, would further allow for new kinds of interactive discussions, involvements, and presentations. All in all, the creation of a jazz/media complex offered the very real possibility of bringing a new visibility to the arts and media in Newark at a time when jazz as an art form was enjoying a new legitimacy, when the arts programs were being strengthened, and when media was assuming a new prominence in teaching and learning in all subject areas.

The challenge for the complex was to integrate the two existing institutions without compromising their individual functions and specialized needs. Since the media operations, the special rooms, and the exhibition gallery would be open longer hours than the Institute was, it was necessary to enclose the Institute as an enclave, albeit a welcoming one, within the larger complex. It was also necessary to ensure that the entrance way and paths to Media Services, to the multipurpose room, and to the group study rooms were clear, that the two departments had good sightlines to facilitate the assisting of users and visitors in their areas, as well as in the gallery and other public areas, and that there were appropriate security systems in place. A new building-wide security system needed to be designed to address the concerns that the addition of a unique collection with state-of-the-art audiovisual and interactive video equipment and computers would bring to the existing facility.

Telecommunication needs were also a major focus. All departments needed to be appropriately wired to allow the microcomputers and terminals to be attached to the Campus' fiber-optic backbone, and sufficient conduits were necessary to carry the electrical and telecommunications cabling to the new floors and to extend this infrastructure to the offices, work areas, group study rooms, and public access areas. The jazz/media complex needed electrical support for the climate controls, as well as for the monitors and loudspeakers in the multipurpose room, and the transmitting of video and sound from Media Services to the carrels and respective rooms. 
And finally, the challenge was to design the floor so that it would bring a sense of intimacy and warmth that reflected the subject matter of jazz and that would soften some of the hard rectangular lines that characterized the existing building as a whole and make it more inviting and attractive. This meant that it would be helpful to introduce more variable spaces, such as the diagonally-shaped gallery with its walkthrough kiosks, small, individual listening rooms and media carrels, and the larger rooms for groups, as well as to choose materials, colors, and textures with this goal in mind. It was important to everyone that the new complex appeal to the spirit, as well as to the intellect.

\section{The Public Services and Lobby Areas}

In the public services area on the main floor, the challenge was somewhat different - the alleviation of the crowdedness in one of the busiest areas in the Library when the new space initially made available was along the perimeter of the other wing. The extent of the renovation that this would entail turned out to be costly, and an alternative plan was developed that focused on the upgrading and expansion of the lobby and that would make available new space for the several operations in reference, intralibrary loan, circulation, and reserve. In essence, the reference area would expand into a reconfigured lobby and out onto the plaza, and the circulation and reserve areas would be enlarged and made more distinct. The entrance ways to the building would shift southward, creating a new sense of cohesion and harmony for the facility as a whole. There would also be new internal entrances to each of the wings that would reflect a functional unity of the two spaces that had heretofore been lacking. A new elevator would be located in the lobby, and a new staircase, also in the lobby, would lead to the lower level, providing a better linking of the vertical with the horizontal, and making it easier for users to reach desired areas. The new lobby staircase would also address, in part, the heavy traffic in the reference room that was for non-reference purposes, drawn by the staircase in that wing. In the lower level, the new lobby staircase would open up an enlarged periodical shelving and reading area, highlighting (and actually providing new light for) this part of the collections that was so essential to the work of graduate students. The lobby would also have a new photocopying room that would facilitate the copying of both reserve and reference materials, and a new computerized orientation center. In essence, the upgraded lobby would make it easier for students and the Library's other patrons to master the 
layout of the building and, hopefully, to gain a clearer understanding of an increasingly complex operation.

The planning strategy that proved to be most helpful in the identification of operations that could or could not be transferred was the listing of functions by zone of desired physical proximity to the reference desk. The reference offices, for example, were considered to be in a zone that did not require a close proximity to the desk, and so the plan called for their relocation out of the reference area to the other (south) wing, which, except for the administrative offices, was devoted largely to carrels and tables. A segment of the reference collections (the Z's) also fell in the "no proximity absolutely necessary" zone, and the plan also called for its relocation to the south wing.

There would be a new reference desk, somewhat more compact, but still substantial in size, and capable of supporting the electronic, printed, and microform tools that were integral to the reference process. It would have a more prominent focal area for interactions with patrons. There would be a separate storage area for reference room supplies, which, in view of the complexity of the reference operation in terms of the variety of materials required, would be an invaluable addition to the area. The interlibrary loan offices would be appropriately enlarged and situated near the reference desk for easy access by librarians and patrons. The other major change in the room was that the Library's electronic reference tools would be placed together in a compact area that was also close to the reference desk. This would cut down on the librarians' walking (some say running) to more remote areas to assist patrons and would allow a closer monitoring of the machines. It also reflected the strong probability that many of the databases would soon be made available through the campus network and that there would be less need to link a workstation to a particular space. And finally, the relocated reference offices would be enlarged and made more efficient to address the burgeoning activities that took place in them and to provide a better space for interaction with students, faculty, and other patrons.

At the present writing, the planning process has not been completed, and there are still a number of uncertainties with respect to whether or not it will be possible to carry out some of the plans. Nevertheless, there is every expectation that the reconfigured public services area will reflect the strong service ethos that is characteristic of the Library and that the new spatial arrangements will contribute to an increased effectiveness in the operation that can only facilitate the learning that 
takes place when students and others interact with the librarians and staff and with each other in the Library setting.

In summary, the planning for the new Dana Library addition facilitates the adaptation of the building to its changing environment, moving upward and (to some extent) outward, emphasizing the Library's vitality and its centrality to the Campus. With the integration of the Institute of Jazz Studies into the Dana facility, it balances the full-fledged research archive with the other research and instructional collections, linking the musical and oral history traditions with the new media and electronic technologies. The new and reconfigured space allows for flexibilities in teaching methods and learning styles and for changes in information technologies in an environment that can only enhance the public services programs. All in all, the new addition should facilitate the encouragement and fostering of a learning that is interactional and involving in concert with the educational and service mission of the Newark Campus and the University Libraries. It should reflect and further the creation of a community for learning and research in Newark.

\section{Notes}

${ }^{1}$ Kuh, G.D., J.H. Schuh, \& E.J. White \& Associates. Involving colleges: successful approaches to fostering student learning and development outside the classroom. San F rancisco: Jossey-Bass, 1991.

${ }^{2}$ Rutgers University Libraries. The Rutgers Advantage: A I.ong-Range Plan for the Libraries. New Brunswick, NJ, 1988.

${ }^{3}$ Mullins, L.S., ed. Planning for an Addition to the John Cotton Dana Library, Rutgers University Libraries, Newark Campus: A Needs Assessment. Prepared by the faculty and staff of the Dana Library and the Institute of Jazz Studies under the direction of Lynn S. Mullins, Director (Newark, NJ: John Cotton Dana Library, Rutgers University Libraries, 1989), pp. 5-9.

${ }^{4}$ See footnote 3 . 


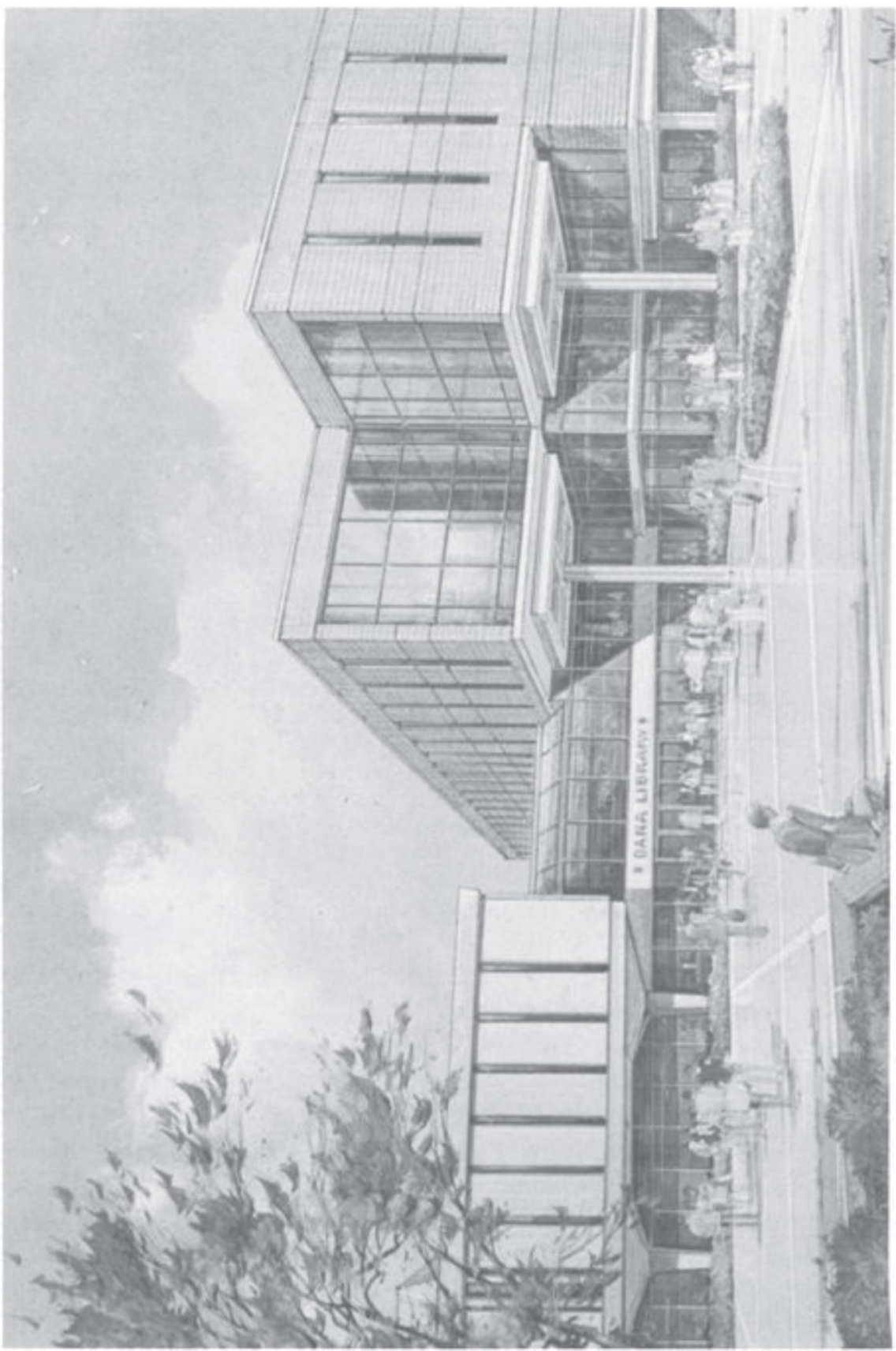

Fig. 4.1 Artist's Rendering of the Expanded Dana Library on RutgersNewark Campus 


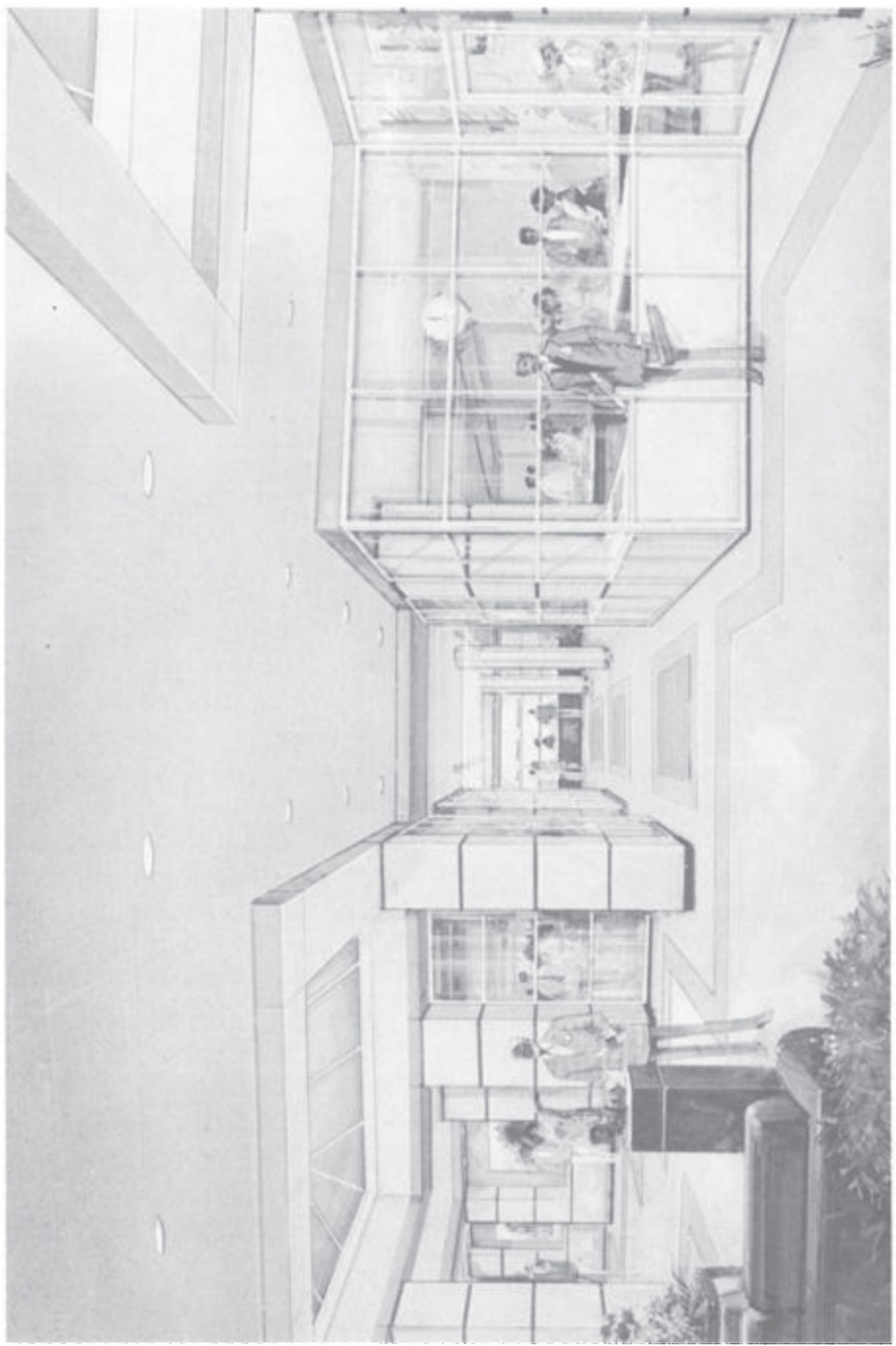

Fig. 4.2 Institute of Jazz Studies/Media Services-Fourth Floor of Dana Library Addition 